\title{
Analysis of Different Breed of Protein Fibres and their Influence on Mechanical Properties of Woollen Blend Yarns
}

\author{
Audronè RAGAIŠIENE் *, Jolita RUSINAVIČIŪTĖ, Daiva MILAŠIENE்
}

Faculty of Mechanical Engineering and Design, Kaunas University of Technology, Studentu str. 56, LT-51424 Kaunas, Lithuania

cross' $^{\text {ref }}$ http://dx.doi.org/10.5755/j01.ms.22.3.8974

Received 22 December 2014; accepted 15 July 2015

\begin{abstract}
The aim of this research was to analyse possibilities of making different woollen blend yarns with sheep's wool and dog's hair fibers and to investigate geometrical and mechanical properties of these yarns. In this paper sheep's wool and dogs' hair fibers were compared one with other in different geometrical (fibre surface, length, diameter, linear density) and mechanical (breaking tenacity, elongation at break, breaking toughness) properties. It was estimated that the sheep's and the dog's fibers are visually very different, they have various types of scales, also most of the dog's hair have channels inside them. On the next stage of this work the woollen blend yarns were made by mixing the wool of German Blackface sheep with different breed (English Spaniel, Poodle, Yorkshire Terrier) dogs' hair 15\%, $25 \%$ and $35 \%$. After evaluating the linear density and mechanical properties of woollen blend yarns, it was estimated that influence of fiber composition in the yarns on these properties is different. Different values of the investigated properties are mostly influenced by spinning system of these yarns. The condenser spinning system affects inequality and unpredictable properties of woollen blend yarns. Also, obtained results depend on the breed of protein fibers, hairy surface, hollow structure and bending rigidity of fiber, the technological process or even compatibility of used devices.

Keywords: protein fibre, geometrical properties, mechanical properties, fibre structure, woollen blend yarns.
\end{abstract}

\section{INTRODUCTION}

The wool has a unique structure: it consists of two major morphological parts (the cuticle and the cortex) and a scale-like particle on the cortex along the fibre length [1-3]. Zimmerman et al. have found that there is a correlation between the surface change (using specific high resolution force spectroscopy) and the fibre morphology [1]. The scale structure of the cuticle is a very important felting property of the wool fibre [2]. The results of another paper [3] indicate the number of abrasion/bending cycles at fibre break, which relates with the structure of scale: alpaca fibres are more abrasion-resistant than the wool of a similar diameter. Alpaca fibres have much lower scale of thickness comparing to the wool fibres. The scale and staple crimp affect the quality, geometrical and mechanical properties of wool products [4-5]. Lijing et al. [4] have studied the wool and the alpaca fibre curvature; it's variation during the time of a fibre processing and the quality of wool products. His study revealed the effect on wool fibre crimp. Varley analysed the sequential scale height of Chinese cashmere, merino wool and alpaca fibres [5]. The diameter of the wool fibre is the main criterion, which determines the trading prices, the processing performance and the usage of wool in general [6-9]. Oi et al. have used two different methods (Projection microscope and Optical Fibre Diameter Analyser) to measure the diameter of the wool and mohair fibres [8]. Variation in diameter determines the rupture of the yarn during the spinning process, yarn count and yarn uniformity [9]. Wool fibre's diameter depends on many

\footnotetext{
* Corresponding author. Tel.: +370-37-353862; fax.: +370-37-353989. E-mail address: audrone.ragaisiene@ktu.lt (A. Ragaišienè)
}

factors: the nutrition of the animal, animal age [7], the region of the animal [10] animal colour [11] or even genetic and environmental indices [12]. Both length growth and diameter of wool fibre respond to changes in nutrient supply [13]. Research [11] revealed the connection between the fibre diameter and the cleanness of the colour. There are several factors, which either affect the colour measurement or susceptibility of the fibre to yellowing. Khan et al. [12] established that the most important parameters, which affect the quality of the woollen yarns are genetic and environmental factors. The wool is affected by the same bacterial, viral, fungal diseases. Treigiene obtained that the treatment of the wool fibre at relatively low temperature changed the color of the wool fibre [14]. Dry and especially wet wool fibers changed their colors more intensively reacting to prolonged heating time. A combination of the fibre characteristics including surface, roughness, bending stiffness, extensibility strongly influence the mechanical properties of the blend yarns [3]. So the aim of this research was to analyse the possibility of making different woollen blend yarns with sheep's wool and dog's hair fibre, to compare geometrical and mechanical properties of these fibres, to make woollen blend yarns with $15 \%, 25 \%$ and $35 \%$ dog's hair and to investigate different properties of these yarns.

\section{MATERIALS}

German Blackface sheep's wool (S1), Romanov sheep's wool (S2) and dog's hair fibres, which were combed from different kind of dogs: English Spaniel (D1), Poodle (D2) and Yorkshire Terrier (D3), were used in this experiment. Some blends from German Blackface sheep wool and every type of dog hair fibre of different 
composition $(15 \%, 25 \%$ and $35 \%)$ were made in this paper. Woollen blend yarns were named: S15, S25, S35 - English Spaniel/German Blackface sheep; P15, P25 and P35-Poodle/German Blackface sheep and YT15, YT25 and YT35-Yorkshire Terrier/German Blackface sheep.

\section{METHODS}

Firstly the photographs of the surface and crosssection of all measured fibres were made in this research. They were taken using a scanning electron microscope (SEM) Quanta-200 FEG (FEI), magnification $2000-3000 \times$, scale $30-200 \mu \mathrm{m}$. 10 images with diameter and cross-section measurement were made for each fibre. Then two hundred hair were taken from every breed for length and diameter measurement. The fibre diameter was estimated with an optical microscope "Ascania" and a digital camera "SMZ 800 Nicon". Magnification was $80 \times$, Metric 7.0 PE-Live program was used. Fibre length was calculated by the length meter FM-04/b ("Mettler Toledo", Switzerland). The linear density of wool was measured from the fibre bundle as specified in standard ASTM D 1294-95a [15]. The length meter FM-04/b ("Mettler Toledo", Switzerland) was used for the measurement of linear density: each type of fibre bundle was pressed with the metal press of length meter with one end and the bundle was combed in that position. The combed bundle was cut off in length $(l=5 \mathrm{~cm})$. It was repeated 5 times for every bundle as specified in ISO 920:1976 [16]. Then each example was weighed and the number of fibres was calculated.

The linear density (tex) of each bundle was determined by this formula:

$T=\frac{m}{l \times n}$,

where $T$ is linear density, tex; $m$ is the mass of the fibre bundle, $\mathrm{g}$; $l$ is the length of the fibre in the bundle, $\mathrm{mm}$; and $n$ is the number of fibres in the bundle.

One hundred hair was taken from each different type of the fibre and every hair was researched with Strength Tester, BDO-FBO.5 TH (,Zwick/Roell”, Germany). The experiment was performed as specified in standard ISO 5079:1995 [17]. The experimental length of the fibre was $20 \mathrm{~mm}$, initial stress $-0.5 \mathrm{cN}$. The speed of the clamp movement was $10 \mathrm{~mm} / \mathrm{min}$. The linear density of all type woollen blend yarns was determined as specified in standard ISO 2060 [18]. Each type of yarns was cut off in length $(l=1 \mathrm{~m})$ and weighed using digital weighing machine EW 150-3M (,Kern \& Sohn GmbH“, Germany). The mechanical properties of investigated yarns were researched with Strength Tester Zwick/Z005 (,Zwick/Roell”, Germany) as specified in the standard ISO 2062 [19]. Experimental length of yarns was $500 \mathrm{~mm}$, initial stress $-2 \mathrm{cN}$. The speed of the clamp movement was $500 \mathrm{~mm} / \mathrm{min}$.

\section{RESULTS}

Scanning electron microscope (SEM) images of wool and dog's hair fibre are shown in Fig. 1. It can be seen (Fig. 1) that sheep's wool fibres S1 and S2 have different structure of the surface and irregular round form crosssection, there are no channels inside the hair.

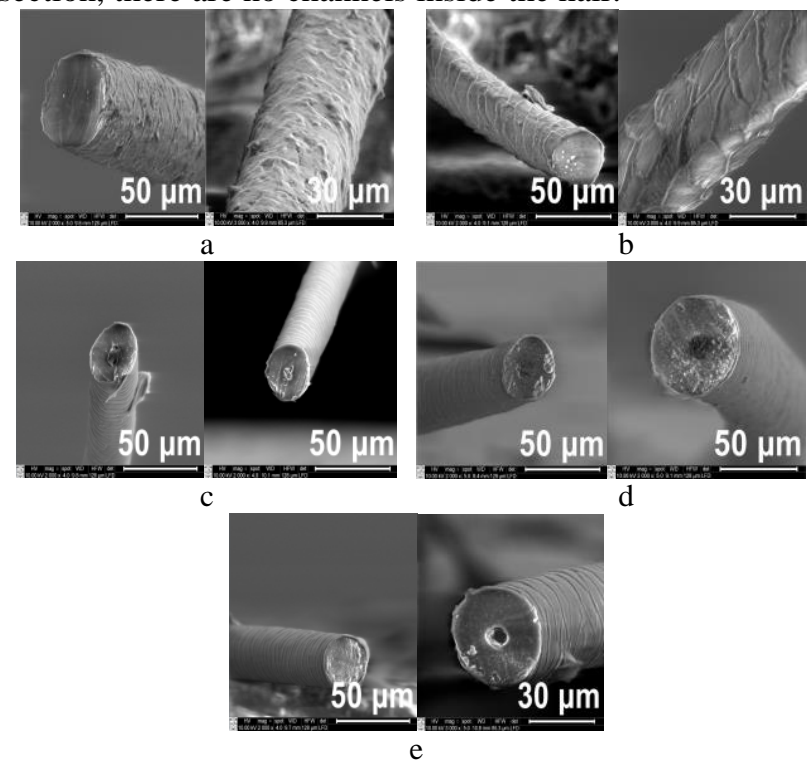

Fig. 1. Sheep's wool and dog's hair fibre surface and crosssection: a-German Blackface sheep; b-Romanov sheep; c-English Spaniel dog; d-Poodle dog; e-Yorkshire Terrier dog

Longitudinal images show that the surface of the fibre S2 is smoother and more embossed than fiber S1 surface. Fig. 1 showed that fibers D1, D2 and D3 have typical wool scales on the surface, the structure of scale is specific and differ from the sheep's wool fibers S1 and S2. There are more scales on the surface of investigated dog's fibers than on fibre S1, the scales of dog's hair fibers are smaller, more delicate and similar to alpaca wool fibre, besides they have channels inside [5, 20]. It was found that the channels inside dog's hair have round form and they are located in the centre of the fibers. Furthermore, it was found that the type of channel of the investigated fibres is different: fibres D1 and D2 have porous channels, fibre D3 have hollow type of the channel inside the hair. SEM images (Fig. 1) showed that fibers D1, D2 and D3 have irregular round cross-section and the same irregular round form channel inside the fibre. Similar results in structure are noticed in the cross-section of Chow-chow, Pekingese dog's hair and primitive Lithuanian sheep's fibers that were found in our previous research [21].

Submitted SEM images revealed that the experimental value of fibre D1 diameter varied in $27.88-31.97 \mu \mathrm{m}$ range and the experimental values of the channel diameter is $5-9 \mu \mathrm{m}$. It means that the channel takes about $18-29 \%$ volume of fibre D1. Fibre D2 with the experimental value of diameter $33 \mu \mathrm{m}$ has the channel inside with diameter $14 \mu \mathrm{m}$. So it takes about $42 \%$ volume of D2. Moreover fibre D2 with the experimental value of diameter $46-52 \mu \mathrm{m}$ has a channel with diameter of $14 \mu \mathrm{m}$ too. These results demonstrate that sometimes thicker hair has a thicker channel inside, but this does not refer to all the cases. Thus diameter of the hair not necessarily affects diameter of the channel. Probably it does not only depend on the breed of wool and hair, but on the stage of hair growth, the time of cut the hair, nutrition and even grazing place too. 
Fibre D3 has a channel inside the hair with an experimental value of diameter $39 \mu \mathrm{m}$ and it takes $20 \%$ volume of D3. An interesting fact is that fibre D3 with an experimental value of diameter $29-33 \mu \mathrm{m}$ do not have any channel inside. This analysis indicates that the presence of the channel depends not just on diameter of the fibre, but from the breed and earlier mentioned factors too. The proof of this is fibers S1, S2 and D3. All of them have very similar experimental values of diameter but not all have the channels inside.

Diameter and length are very important properties of the wool fibre. Table 1 presents calculated values (estimated with optical microscope "Ascania") of geometrical properties i.e. average value $(\chi)$, coefficient of variation $(V)$ and absolute random error $(\Delta)$.

Table 1. Summary of sheep's and dog's wool fiber geometrical properties

\begin{tabular}{|c|c|c|c|c|}
\hline \multirow{2}{*}{$\begin{array}{c}\text { Fibre } \\
\text { symbol }\end{array}$} & \multicolumn{2}{|c|}{ Fibre lenght, $\mathrm{mm}$} & \multicolumn{2}{c|}{ Fibre diameter, $\mu \mathrm{m}$} \\
\cline { 2 - 5 } & $x, \mathrm{~mm}$ & $V, \%$ & $x, \mu \mathrm{m}$ & $V, \%$ \\
\hline S1 & $88.63 \pm 0.62$ & 5.03 & $30.00 \pm 0.31$ & 7.48 \\
\hline S2 & $136.53 \pm 1.58$ & 8.30 & $32.50 \pm 0.44$ & 9.70 \\
\hline D1 & $47.39 \pm 0.64$ & 9.73 & $28.20 \pm 0.40$ & 10.20 \\
\hline D2 & $29.32 \pm 0.42$ & 10.34 & $21.73 \pm 0.38$ & 12.43 \\
\hline D3 & $49.80 \pm 0.47$ & 6.71 & $29.55 \pm 0.33$ & 8.05 \\
\hline
\end{tabular}

It is noticed that sheep's wool fibre S1 and S2 have the highest values of diameter and length of all measured fibers. Very similar results in diameter and length of the fibers were received in other research [22-23].

Fiber D1 and D2 diameter is comparable to Turkish Angora, Van cats [25] and Chokla wool [25] diameter. Mean fibre diameter of Rambouillet, Columbia and crossbred rows was measured in [6] and the result (25-27 $\mu \mathrm{m})$ is like in fibre D1. The average diameter of wool and mohair fibers is very similar too. It was measured in [9]: using projection microscope $(18.9-28.2 \mu \mathrm{m})$ and optical fibre diameter analyser $(19.0-28.1 \mu \mathrm{m})$. Fibre D3 has the medium value of diameter $(29.55 \mu \mathrm{m})$ compared with other mentioned fibers and this result is similar to diameter of Camel hair [24].

$\mathrm{CV}$ shows the dispersion in the variable. It was found that variation of diameter of sheep wool was $24-26 \%$ and variation of length $22-23 \%$ [10]. Although average values of diameter and length measured in [10] are similar to fibres D1, D2 and S1, S2, variation of diameter of investigated fibres is two times less $7-12 \%$. It can be seen from Table 1 that fibres D3, S1 and S2 have similar diameter $(29.55-30.00-32.5 \mu \mathrm{m})$, but completely different length (49.80-88.63-136.5 mm).

In this investigation values of linear density obtained were compared with that determined by formula [20]:

$T=\frac{\pi}{4} \times d^{2} \times \rho \times 10^{-3}$,

where $d$ is the fibre diameter, $\mu \mathrm{m} ; \rho$ is the fibre density $1.32 \mathrm{~g} / \mathrm{cm}^{2}$.

The difference between theoretical and experimental linear density of all fibres $\mathrm{S} 1$ and $\mathrm{S} 2$ is $11-17 \%$. Eq. 2 highlights the fact, that the real diameter of all fibres has irregular round form. In Eq. 2 there are unconsidered channels and air gaps, which were found in each hair of the dog cross-section. It was established, that all values of theoretical linear density were lower than experimental.

It was estimated that the fibre S2 has the highest values of theoretical (1.094 tex) and experimental (1.28 tex) linear density of all measured fibres. Fibre S2 has very specific textured surface with scales and this could influence the results of linear density. It was observed that fibre $\mathrm{S} 1$ is $8 \%$ thinner than fibre $\mathrm{S} 2$ and it has $19 \%$ lower experimental linear density.

Fibres D3 and S1 have very similar values of diameter $(29.55-30.00 \mu \mathrm{m}), \quad$ theoretical $(0.91-0.93$ tex $)$ and experimental (1.025-1.04 tex) linear density, while D3 has a channel inside. It was found previously that the channel of fibre D3 was very spongy and porous and this could influence the results. It was measured in this research that the fibre D3 was the thickest $(29.55 \mu \mathrm{m})$, the longest $(49.79 \mathrm{~mm})$ and had the highest value of experimental linear density (1.025 tex) of all dogs' hair.

The maximum inequality (16\%) among theoretical and experimental values of linear density between dog's hair fibres has D2 and it can be explained by channels, which take even $65 \%$ of D2 volume.

Breaking tenacity, elongation at break and breaking toughness average values $(x)$, coefficient of variation $(V)$ and absolute random error $(\Delta)$ of every investigated fibre are presented in Table 2.

Table 2. Summary of sheep's wool and dog's hair fibre mechanical properties

\begin{tabular}{|c|c|c|c|c|c|}
\hline $\begin{array}{c}\text { Fibre } \\
\text { symbol }\end{array}$ & $\mathrm{S} 1$ & $\mathrm{~S} 2$ & $\mathrm{D} 1$ & $\mathrm{D} 2$ & $\mathrm{D} 3$ \\
\hline \multicolumn{7}{|c|}{ Breaking tenacity, cN/tex } \\
\hline$x, \mathrm{cN} / \mathrm{tex}$ & 19.29 & 37.04 & 12.70 & 41.69 & 33.18 \\
\hline$\Delta$, tex & \pm 4.49 & \pm 3.12 & \pm 1.11 & \pm 3.67 & \pm 1.22 \\
\hline$V, \%$ & 30.71 & 23.72 & 23.67 & 25.77 & 24.25 \\
\hline \multicolumn{7}{|c|}{ Elongation at break, \% } \\
\hline$x, \%$ & 34.40 & 54.63 & 36.59 & 39.86 & 43.78 \\
\hline$\Delta, \%$ & \pm 1.24 & \pm 2.89 & \pm 1.14 & \pm 1.72 & \pm 1.23 \\
\hline$V, \%$ & 19.67 & 18.47 & 16.43 & 21.35 & 16.53 \\
\hline \multicolumn{7}{|c|}{ Breaking toughness, $\mathrm{kJ} /$ tex } \\
\hline$x, \mathrm{~kJ} / \mathrm{tex}$ & 0.51 & 1.47 & 0.34 & 1.26 & 1.11 \\
\hline$\Delta, \mathrm{kJ} / \mathrm{tex}$ & \pm 0.02 & \pm 0.06 & \pm 0.01 & \pm 0.05 & \pm 0.04 \\
\hline$V, \%$ & 41.22 & 35.82 & 33.00 & 38.88 & 31.09 \\
\hline
\end{tabular}

It was measured previously that sheep's wool fibres S1 and S2 have similar diameter $(30.00-32.50 \mu \mathrm{m})$, but different length $(88.63-136.53 \mathrm{~mm})$. Table 2 shows that fibre $\mathrm{S} 1$ is shorter than fibre $\mathrm{S} 2$ in $35 \%$ and weaker in $49 \%$. This could be explained by the unique structure of $\mathrm{S} 2$. The surface of fibre S2 is more whole, the structure seems stronger and the scales are located more frequently. It was found, that both fibers do not have channels inside, they have similar linear density, but mechanical indices of these fibres are different (see Table 2). There was estimated falling tendency between geometrical indices of fibre S2 and breaking toughness: fibre S2 has the highest values of diameter, length and breaking toughness of all mentioned fibers. Fibre D2 has the lowest values of geometrical properties and the highest value of breaking tenacity and breaking toughness of all dog's hair fibres. It was established (Table 2) that fibre D3 has medium value 
of breaking tenacity, while diameter and length of fibre D3 is the highest of all dog's hair fibres. So the converse tendency was found with fibre D2. It should be noted that fibre D2 has similar values of diameter and elongation at break with alpaca wool in [3], but three times higher breaking tenacity. Breaking force of all mentioned fibres vary from $10.41 \mathrm{cN}$ to $40.52 \mathrm{cN}$, work of break $0.28-1.61 \mathrm{~kJ}$. It was mentioned that fibers D1 and D3 have similar values of diameter $(28.20-29.55 \mu \mathrm{m})$, length $(47.39-49.80 \mathrm{~mm})$, linear density $(0.82-0.91 \mathrm{tex})$, elongation at break (36.59-43.78\%), but fibre D1 has lower value of breaking tenacity and breaking toughness nearly three times lower than fibre D3.

On the second stage of this research, woollen blend yarns with $15 \%, 25 \%$ and $35 \%$ of dog's hair fibers using condenser spinning system were made. The condenser spinning system tends to be used to process all blends of different fibers, which vary in length and diameter. The system is capable to handle the poorer types of wool, especially those that are short and tender (i.e. have low strength). Sheep's wool and dog's hair fibers were opened with periodic operation opener ,TP-90 SI“, then the batching was made (emulsion ,Serbana UN" with water in ratio $1: 10$ ), the second opening and blending. After a few hours of relaxation the blends were carded (three-card woolen set with condenser „Befama“, Poland).

Then ring spinning and winding process was performed. In textiles it is very important to choose the right component for the blend. Fibre length, diameter, linear density, breaking tenacity, elongation at break and other strength properties are very important for yarn parameters of these fibers.

Table 3 illustrates geometrical and mechanical properties of woollen blend yarns with dog's hair fibre: average values $(\mathrm{x})$ and coefficient of variation $(\mathrm{V})$.

It can be seen from Table 3 that woollen blend yarns with $15 \%$ dog's hair P15, S15 and YT15 have the highest values of breaking tenacity $(2.91-3.81 \mathrm{cN} / \mathrm{tex})$ and elongation at break (15.5-17.8\%). It was estimated that fibre D2 has the lowest diameter, length, linear density and breaking tenacity of all previously measured fibers. Now it can be seen from Table 3 that the woollen blend yarn P25 has the lowest values of breaking tenacity and elongation at break of all the measured yarns.
However, in general the analysis of mechanical indices of woollen blend yarn allowed to indicate that the yarns S35 and P35 (with $35 \%$ dog's hair) have higher values of breaking tenacity and elongation at break, yarns S35, P35 and YT35 have higher values of breaking toughness than yarn with $25 \%$ dog's hair fibre S25, P25 and YT25. Nevertheless, the clear tendencies of changing the linear density and the mechanical properties of the woollen blend yarn in this stage of the investigation have not been identified so far. Only Yorkshire Terrier breed dog's hair composition influences them much more clearly, i. e. breaking tenacity and elongation at break of these yarns have tendency to decrease. There are a few reasons of these results: three experiment points in this stage of research; slippage of shorter dog's fibers during tensile testing; the condenser spinning system. Of course, linear density and, especially yarn twist, could be affected on bending rigidity of hairy fibers that have lower diameters and hollow structures.

So, it was estimated that breed of protein fibers, hairy surface of fiber, the technological process or even compatibility of devices influence uniformity of yarn in the length unit. The condenser spinning system affects inequality and unpredictable properties of woollen blend yarns.

Woollen blend yarns with dog's hair protect people not only from cold but also from joints diseases. Knitwear made from these yarns is used in natural medicine for centuries. On the next stage of this investigation it is planned to make knitted fabrics of woollen blend yarns and to study their properties (geometrical, mechanical and thermo-mechanical)

\section{CONCLUSIONS}

It was estimated that investigated dog's hair fibers have more crimp and a smoother surface than sheep's wool fibre, also dog's hair fibers have irregular round shape channels inside the hair. The geometrical properties of fibers and diameter of channel depends on many factors: nutrition, animal age, animal body region, the stage of hair growth, the time of cut the hair, nutrition, grazing place. It was established that the geometrical properties of the fibers influence their mechanical properties.

Table 3. Linear density, breaking tenacity, elongation at break and breaking toughness of woollen yarn

\begin{tabular}{|c|c|c|c|c|c|c|c|c|c|}
\hline Fiber symbol & $\mathrm{S} 15$ & $\mathrm{P} 15$ & YT15 & S25 & $\mathrm{P} 25$ & YT25 & S35 & $\mathrm{P} 35$ & YT35 \\
\hline \multicolumn{10}{|c|}{ Linear density, tex } \\
\hline$x$, tex & 207.49 & 249.18 & 203.28 & 193.20 & 203.90 & 218.20 & 209.80 & 230.90 & 217.80 \\
\hline$V, \%$ & 12.48 & 9.25 & 10.42 & 5.24 & 7.35 & 6.77 & 6.04 & 3.62 & 6.89 \\
\hline \multicolumn{10}{|c|}{ Breaking tenacity, $\mathrm{cN} /$ tex } \\
\hline$x, \mathrm{cN} / \mathrm{tex}$ & 3.36 & 3.81 & 2.91 & 1.90 & 1.53 & 2.07 & 2.04 & 2.32 & 1.88 \\
\hline$V, \%$ & 22.4 & 9.3 & 13.2 & 20.8 & 17.7 & 22.8 & 12.9 & 15.1 & 16.1 \\
\hline \multicolumn{10}{|c|}{ Elongation at break, $\%$} \\
\hline$x, \%$ & 16.7 & 17.8 & 15.5 & 9.8 & 8.9 & 12.2 & 11.4 & 13.6 & 10.9 \\
\hline$V, \%$ & 11.8 & 9.8 & 11.2 & 17.2 & 20.2 & 19.8 & 16.7 & 16.0 & 13.9 \\
\hline \multicolumn{10}{|c|}{ Breaking toughness, $\mathrm{kJ} / \mathrm{tex}$} \\
\hline$x, \mathrm{~kJ} / \mathrm{tex}$ & 2.29 & 2.57 & 1.81 & 0.77 & 0.58 & 1.07 & 0.98 & 1.29 & 0.87 \\
\hline$V, \%$ & 29.3 & 15.5 & 20.5 & 34.5 & 35.1 & 44.7 & 26.8 & 28.5 & 25.3 \\
\hline
\end{tabular}


Woollen blend yarns with $15 \%$ of dog's hair have the highest values of breaking tenacity and elongation at break of all mentioned yarns. Yarns with $35 \%$ of dog's hair have higher values of breaking tenacity, elongation at break and work of rupture than yarn with $25 \%$ of dog's hair. In general, there are no more falling tendencies between fiber composition in the yarns and mechanical properties of woollen blend yarns. Breed of protein fibers, hairy surface of fiber, the technological process or even compatibility of devices affect uniformity of yarn in the length unit. Moreover, the condenser spinning system affects inequality and unpredictable properties of woollen blend yarns.

\section{REFERENCES}

1. Zimmerman, B., Chow, J., Abbot, A., Ellison, M., Kennedy, M., Dean, D. Variation of Surface Change along the Surface of Wool Fibers Assesed by High - Resolution Force Spectroscopy Journal of Engineered Fibers and Fabrics 6 (2) 2011: pp. 61-66.

2. Kotlinska, A., Lipp-Symonowicz, B. Research on the Enzymatic Treatment of Wool Fibres and Changes in Selected Properties of Wool Fibres \& Textile in Eastern Europe 193 (86) 2011: pp. 88-93.

3. Liu, X., Hurren, C., Wang, X. A Comparative Study of The Abrasion Fatigue And Resistance To Compression Properties of Wool And Alpaka Fibres Proceedings of the 11 th International Wool Research Conference, 2005.

4. Lijing, W., Xin, L., Xungai, W. Changes in fibre curvature during the processing of wool and alpaca fibres and their blends Proceedings of The Textile Institute 83rd World Conference 2004: pp. 1-6.

5. Varley, A. A Modified Method of Cuticle Scale Height Determination for Animal Fibers AATCC Review 6 (5) 2006: pp. $38-41$.

6. Iman, N.Y., Johnson, C.L., Russell, W.C., Stobart, R.H. Estimation of Genetic Parameters for Wool Fiber Diameter Measures Journal of Animal Science 70 1992: pp. $1110-1115$.

7. Brown, D.J., Crook, B.J., Purvis, I.W. Variation in fibre diameter profile characteristics between wool staples in Merino sheep Wool Technology and Sheep Breeding 48 (2) 2000: pp. 86-93.

8. Qi, K., Lupton, C.J., Pfeiffer, F.A., Minikhiem, D.L. Evaluation of The Optical Fibre Diameter Analyser (OFDA) For Measuring Fiber Diameter Parameters of Sheep And Goats Journal of Animal Science 72 1994: pp. $1675-1679$.

9. Lupton, C.J. Standart Deviation of Fiber Diameter and other Characteristics of Uniter States Wool Sheep \&Goat Research Journal 11 (3) 1995: pp. 111-121.

10. Enciu, A., Vicovan, P.G., Calin, I., Zamfir, C.Z., Nicolescu, A. Estimates of Morphological Structure of Fleece and Variation of Wool Qualitative Traids oh Different Body Region of Palas Meat Line Sheep
Universitatea de Ştiinţe Agricole şi MedicinăVeterinarăIaşi 53 2010: pp. 370-376.

11. Fleet, M.R., Millington, K.R., Smith, D.H., Grimson, R.J. Association of fibre diameter with wool colour in a south Australian selection flock Proceedings of the 18th Conference of the Association for the Advancement of Animal Breeding and Genetics 18 2009: pp. 556-559.

12. Khan, M.J., Abbas, A., Ayaz, M., Naeem, M., Akhter, M.S., Soomro, M.H. Factors Affecting Wool Quality and Quantity In Sheep African Journal of Biotechnology 11 (73) 2012: pp. 13761-13766.

13. Reis, P.J., Sahlu, T. The Nutritional Control of The Growth And Properties of Mohair And Wool Fibres: A Comparative Review Journal of Animal Science 72 1994: pp. 1899-1907.

14. Treigienė, R. The Influence of Physical Factors on Wool Fibre Colour Changes Materials Science $16(4)$ 2010: pp. 341-345.

15. ASTM Designation: D 1294-95a. Standard Test Method for Tensile Strength and Breaking Tenacity of Wool Fiber Bundles 1-in. (25.4-mmm) Gage Length.

16. International standard ISO 920:1976. Wool - Determination of fibre length (barbe and hauteur) using a comb sviter.

17. International standard ISO 5079:1995. Textiles-FibresDetermination of breaking force and elongation at break of individual fibres.

18. International standard ISO 2060. Textiles - Yarn from packages - Determination of linear density (mass per unit length) by the skein method.

19. International standard ISO 2062. Textiles - Yarn from packages - Determination of single-end breaking force and elongation at break.

20. Czaplicki, Z. Properties and Structure of Polish Alpaca Wool Fibres \& Textile in Eastern Europe $20(1(90))$ 2012: pp. $8-12$.

21. Ragaišienè, A., Rusinavičiūtė, J. Comperative Investigation of Mechanical Indices of Sheep's Wool and Dog Hair Fibre Fibres \& Textile in Eastern Europe 20 (5 (94)) 2012: pp. $33-37$.

22. Scobie, D.D., Bray, A.R., Maher, A.P., Smith, M.C., Merrick, N.C. Staple Strength in Crossbred Wool: The Sensible Solution Proceedings of the Australian Society of Animal Production 1994 biennial conference 20 1994: pp. $301-304$

23. Helal, A., Fayed, A.M. Wool Characteristics of Sheep Fed on Halopnyte Plants Ensiled by Some Biological Treatments Journal of Sheep and Goat Sciences 8 (1) 2013: pp. $131-139$.

24. Erat, S., Arikan, S. The hair characteristics of Turkish Angora and Van Cats Turkish Journal of Veterinary \& Animal Sciences 36 (3) 2012: pp. 215-221.

25. Shakyawar, D.B., Patni, P.C., Gupta, N.P. Studies of animal fibre blended handmade felts: Part II - Frictional, compressional and thermal properties Indian Journal of Fibre \& Textile Research 32 2007: pp. 301-305. 